\title{
High Molecular Weight Kininogen Deficiency
}

National Cancer Institute

\section{Source}

National Cancer Institute. High Molecular Weight Kininogen Deficiency. NCI Thesaurus.

Code C98946.

A rare autosomal recessive inherited disorder characterized by prolonged partial thromboplastin time and absence of bleeding diathesis. 